\title{
COMPARAÇÃO DO HABITO ALIMENTAR DE EQÜÍDEOS SOB PASTEJO
}

\author{
COMPARISON OF FOOD HABIT OF HORSES AND MULES UNDER GRAZING
}

\author{
Zanine, A.M. ${ }^{1}$, B.R. Vieira ${ }^{2 A}$, D.J. Ferreira ${ }^{2 B}$, A.J.M. Vieira ${ }^{3}$ e R.P. Lana ${ }^{2 C}$
}

\begin{abstract}
${ }^{1}$ Universidade Federal de Mato Grosso. Rua Anísio Braga nº 144. Bairro Coopharondon. CEP 78740-355. Rondonópolis-MT. Brasil. anderson.zanine@ibest.com.br

2Universidade Federal de Viçosa/UFV. Viçosa-MG. Brasil. Aramalhovieira@yahoo.com.br; Bdany_dosanjos@yahoo.com.br; Crlana@ufv.br

${ }^{3}$ Fiscal Federal Agropecuário. Órgão de Atuação. Comissão Executiva do Plano da Lavoura CacaueiraCEPLAC. Bahia-BA. Brasil.
\end{abstract}

\section{PalaVRas chaVe AdicionaIS}

Éguas. Cavalo. Mula. Taxa de bocados.

\section{RESUMO}

Foi conduzido um experimento com o objetivo de avaliar as diferenças no comportamento de eqüídeos em pastagem de coast-cross. O delineamento experimental foi o inteiramente casualizado, com três categorias (cavalos, éguas e mulas) representando os tratamentos, cada um com sete repetições. O período experimental foi de 40 dias, sendo 25 para adaptação dos animais e 15 para avaliações, que consistiram de três repetições, com duração de 24 horas cada, em intervalos de cinco dias. O teste t demonstrou que os cavalos passaram menos tempo pastejando durante o dia (6,38 horas) em relação às éguas ( 8,85 horas) e mulas ( 7,33 horas). Em relação ao tempo total em pastejo, as mulas gastaram mais tempo (14,77 horas), enquanto os cavalos pastejaram durante 11,60 horas. Os cavalos permaneceram maior tempo em ócio que as éguas e mulas, enfatizando a menor exigência nutricional dos cavalos. Não foram observadas diferenças entre cavalos e éguas, com relação à quantidade de bocados por minuto. As éguas e mulas aumentaram o seu tempo de pastejo como forma de atingir suas exigências nutricionais, já que não houve diferença na freqüência de bocados.

\section{SUMMARY}

An experiment was carried out to evaluate the difference among horses and mules in grazing

Recibido: 1-9-07. Aceptado: 1-10-07.

\section{AdDitionAl KEYWORDS}

Mare. Horse. Mule. Bite rate.

behaviour on coast-cross pasture. A completely randomized experimental design with tree categories (horses, mares and mules) as treatments, each with seven repetitions. The experiment lasted 40 days, being 25 for animal adaptation and 15 for evaluation, that consisted of three replicates, with duration of 24 hours each, in intervals of five days. The $t$ test showed that horses grazed less time during the day $(6.38$ hours) than mares ( 8.85 hours) and mules (7.33 hours). In relation to the total grazing time, the mules spent more time (14.77 hours), while the horses grazed during 11.60 hours. Horses stayed larger time in idling than mares and mules, emphasizing the smallest nutritional demand of horses. There was no difference between horses and mares, regarding the number of bites per minute. The mares and mules increased the time of grazing in order to reach their nutritional demands, since there was no difference in the frequency of mouthfuls.

\section{INTRODUÇÃO}

O eqüídeo é um animal que representa sessenta milhões de anos de evolução. Ao longo desse tempo, ele desenvolveu habilidades e características físicas para chegar a sua forma atual. Uma destas características é seu hábito alimentar. O cavalo é um 
animal herbívoro, especializado na digestão de fibras. Para isso, ele desenvolveu bastante o ceco, porção do intestino grosso habitada por bactérias que digerem as fibras da dieta do eqüino e as transformam em nutrientes como energia e vitaminas.

Os cavalos em ambientes naturais gastam de 60 a $70 \%$ do seu tempo pastejando; o restante do tempo é gasto observando outros animais, acariciando-se uns aos outros, correndo ou andando a procura de novas áreas de pasto (Seal e Plotka, 1983).

O padrão usual de pastejo pelos eqüinos é marcado pela rápida apreensão de pequenas quantidades de forragem, a movimentação constante para frente e a mastigação acompanhada da ingestão durante a mastigação (Ralston, 1984). Os eqüídeos, sob pastejo, atendem às suas exigências nutricionais por meio da ingestão de forragem, que em condições extensivas de manejo pode durar mais de 16 horas diária (Zanine et al., 2006ab). O comportamento de pastejo afeta a ingestão e, portanto, a performance do animal, que depende da quantidade de tempo gasto no pastejo, a taxa e o tamanho do bocado.

Objetivou-se com o experimento avaliar o comportamento alimentar a pasto dos eqüídeos e estabelecer as possíveis diferenças.

\section{MATERIALE MÉTODOS}

O experimento foi realizado na Fazenda Itamira, localizada a $20 \mathrm{~km}$ da cidade de Itanhém, Bahia, Brasil. Foram utilizadas pastagens já formadas de capim coast-cross (Cynodon ssp). Essa pastagem foi adubada previamente com $50 \mathrm{~kg}$ de nitrogênio por hectare. Para a análise da composição bromatológica foram coletadas 20 amostras aleatoriamente no pasto, formando uma amostra composta, da qual foram retiradas $100 \mathrm{~g}$ para as análises bromatológicas de acordo com a metodologia descrita por (Silva, 1999). Os valores observados foram: MS $(\%)=33,82 ; \mathrm{PB}(\%)=9,93 ; \mathrm{FDN}(\%)=$
72,$05 ; \operatorname{FDA}(\%)=35,69 ; \operatorname{HEM}(\%)=36,36$; $\operatorname{MM}(\%)=12,25$.

Utilizou-se o método direto para estimativa da disponibilidade de forragem, em 10 subáreas de $1,0 \mathrm{~m}^{2}$ cada, onde a forragem foi cortada rente ao solo. A disponibilidade de forragem foi de 1,72 toneladas de matéria seca por hectare, para o pasto de capim coast-cross. Já a relação lâmina:colmo, determinada nas mesmas subamostras utilizadas para estimativa da disponibilidade de forragem, foi de 2,21:1,00.

Foram utilizadas 7 éguas no terço inicial de gestação, 7 cavalos castrados da raça Mangalarga e 7 mulas, com respectivos pesos médios 538,518 e $360 \mathrm{~kg}$. Eram animais adultos, com idades próximas aos 10 anos, com bom escore corporal, sendo todos os animais criados a pasto com suplementação mineral. O sistema de pastejo foi o de lotação contínua, com taxa de lotação variável, com objetivo de manter as alturas dos pastos em torno de $25 \mathrm{~cm}$. Para tanto, foram utilizados animais reguladores, tendo em vista que o pasto compreendeu uma área de 2,0 ha.

Foi oferecido aos eqüídeos sal mineral à vontade em todo o período experimental, sendo que a adaptação foi feita com 40 dias de antecedência.

O período experimental teve duração de 40 dias, sendo 25 para adaptação dos animais ao pasto e 15 para avaliações. Foram feitas três avaliações com duração de 24 horas cada, realizadas a cada cinco dias, de maneira que a média das três avaliações fosse utilizada nas análises estatísticas. As avaliações foram realizadas nos dias 18, 23 e 28 de janeiro de 2006 . A média das temperaturas foi de $20^{\circ} \mathrm{C}$ durante a noite e de $31^{\circ} \mathrm{C}$ durante o dia, sendo utilizado um termômetro de máxima e de mínima para a medida das temperaturas a cada 30 minutos.

$\mathrm{O}$ delineamento experimental foi $\mathrm{o}$ inteiramente casualizado, sendo os tratamentos os animais (cavalos, éguas e mulas), com 7 repetições ( 7 animais por tratamento). As variáveis analisadas foram: tempo de pastejo diurno, tempo de pastejo noturno, 


\section{COMPARAÇÃO DO HABITO ALIMENTAR DE EQÜÍDEOS SOB PASTEJO}

tempo total de pastejo, tempo de ócio diurno, tempo de ócio noturno, tempo total de ócio, taxa bocados diurna, taxa de bocados noturna, quantidade total de bocados diurno e quantidade total de bocados noturno.

Os tempos de pastejo e ócio foram obtidos por meio de observações visuais dos animais a cada 10 minutos, sendo o tempo total o somatório de vezes nas quais os animais foram observados em determinado estado. Foi considerado como período diurno, aquele das 7 às 18:50 horas, e o período noturno compreendeu o intervalo entre 19 e 6:50 horas. Para a avaliação foram utilizadados dois grupos de avaliadores composto de três pessoas cada, revezando a cada 4 horas. A identificação dos animais foi feita pela coloração da pelagem.

A taxa de bocado foi obtida por meio da contagem direta do total de bocados observados no período de 1 minuto, sendo a resultante da média de observações a cada meia hora, quando os animais estivessem pastejando. O total de bocados foi calculado pelo produto entre a taxa de bocados e o tempo de pastejo, em minutos.

Os dados referentes ao hábito de pastejo foram comparadas pelo teste $t$, ao nível de $5 \%$ de probabilidade. As análises foram

Tabela I. Valores médios e respectivos desvios-padrão dos tempos de pastejo dos eqüídeos nos períodos diurno, noturno e diário. (Grazing times (mean $\pm s d$ ) of equines in the diurnal, nocturnal and whole day periods).

\begin{tabular}{|c|c|c|c|c|}
\hline \multirow{2}{*}{\multicolumn{2}{|c|}{$\mathrm{n}$}} & \multicolumn{3}{|c|}{ Tempo de pastejo (horas) } \\
\hline & & diurno & noturno & diário \\
\hline Cavalo & 7 & $6,38^{\mathrm{b}} \pm 0,28$ & $5,22^{b} \pm 0,21$ & $11,60^{\mathrm{b}} \pm 0,38$ \\
\hline Égua & 7 & $8,85^{a} \pm 0,32$ & $5,41^{\mathrm{b}} \pm 0,24$ & $13,49^{a} \pm 0,43$ \\
\hline Mula & 7 & $7,33^{\mathrm{ab}} \pm 0,29$ & $7,44^{\mathrm{a}} \pm 0,27$ & $14,77^{a} \pm 0,49$ \\
\hline Total & 21 & $22,56 \pm 0,90$ & $18,07 \pm 0,74$ & $39,86 \pm 1,30$ \\
\hline$C V(\%)$ & & 8,75 & 5,30 & 8,80 \\
\hline
\end{tabular}

Médias seguidas pela mesma letra na mesma coluna não diferem $(p>0,05)$ pelo teste $t$. realizadas utilizando-se o pacote estatístico SAEG, 1999.

\section{RESULTADOSEDISCUSSÃO}

Na tabela I pode ser observada a comparação dos tempos de pastejo dos animais no pasto de capim coast-cross. Os cavalos passaram menos tempo pastejando em relação às éguas e os muares no período diurno. Comportamento diferenciado foi observado no período de pastejo noturno em que os muares pastejaram em média 2 horas a mais que os eqüinos.

Para o tempo total em pastejo, as éguas e mulas gastaram mais tempo, em relação aos cavalos. Este fato pode ter ocorrido devido a maiores exigências nutricionais das éguas que estavam no início da gestação e das mulas pela sua maior demanda energética devido a sua maior resistência à fadiga.

No presente experimento, os eqüinos pastejaram mais durante o dia e os muares pastejaram na mesma proporção dia/noite.

Na tabela II encontram-se os valores referentes ao tempo de ócio nas três categorias estudadas. Diferenças significativas foram observadas para o período diurno, em que o maior valor foi verificado para os cavalos e o menor para as éguas, o

Tabela II. Valores médios e respectivos desvios-padrão dos tempos de ócio dos eqüídeos nos períodos diurno, noturno e diário. (Leisure times (mean \pm sd) of equines in the diurnal, nocturnal and whole day periods).

\begin{tabular}{lcccc}
\hline & & \multicolumn{3}{c}{ Tempo de ocio (horas) } \\
& $\mathrm{n}$ & diurno & noturno & diário \\
\hline Cavalo & 7 & $5,62^{\mathrm{a}} \pm 0,23$ & $6,78^{\mathrm{a}} \pm 0,28$ & $12,40^{\mathrm{a}} \pm 0,41$ \\
Égua & 7 & $3,15^{\mathrm{c}} \pm 0,22$ & $6,59^{\mathrm{a}} \pm 0,26$ & $9,74^{\mathrm{b}} \pm 0,35$ \\
Mula & 7 & $4,66^{ \pm} \pm 0,26$ & $3,75^{\mathrm{b}} \pm 0,20$ & $8,41^{\mathrm{b}} \pm 0,31$ \\
Total & 21 & $13,43 \pm 0,70$ & $17,12 \pm 0,74$ & $30,55 \pm 1,10$ \\
CV(\%) & 5,11 & 8,38 & 5,33 \\
\hline
\end{tabular}

Médias seguidas pela mesma letra na mesma coluna não diferem $(p>0,05)$ pelo teste $t$. 
Tabela III. Valores médios das taxas de bocados por minutos durante o dia (TBD) e noite (TBN), e quantidade total de bocados diurno (TTBD) e noturno (TTBN), gasto pelos eqüídeos na pastagem de coast cross. (Mean values of the mouthfuls rate per minute during day (TBD) and night (TBN), and total amount of mouthfuls of day (TTBD) and night (TTBN), expense for the equines on coast cross pasture).

\begin{tabular}{lccccc}
\hline Categorias & $\mathrm{n}$ & TBD & TBN & TTBD & TTBN \\
\hline Cavalo & 7 & $29,50^{\mathrm{a}} \pm 4,54$ & $29,50^{\mathrm{a}} \pm 4,55$ & $11292,60^{\mathrm{a}} \pm 1342$ & $9239,40^{\mathrm{b}} \pm 1456$ \\
Égua & 7 & $28,50^{\mathrm{a}} \pm 3,23$ & $30,00^{\mathrm{a}} \pm 4,23$ & $15133,50^{\mathrm{b}} \pm 1556$ & $9738,00^{\mathrm{ab}} \pm 1897$ \\
Mula & 7 & $25,00^{\mathrm{c}} \pm 2,88$ & $24,00^{\mathrm{b}} \pm 3,21$ & $10995,00^{\mathrm{a}} \pm 1789$ & $10713,60^{\mathrm{a}} \pm 1780$ \\
Total & 21 & $83,00 \pm 10,65$ & $83,5 \pm 11,99$ & $37421,10 \pm 4687$ & $29691,00 \pm 5133$ \\
CV $(\%)$ & & 15,53 & 8,72 & 9,70 & 16,32 \\
\hline
\end{tabular}

Médias seguidas pela mesma letra na mesma coluna não diferem $(p>0,05)$ pelo teste $t$.

que era de se esperar, pois, as éguas passaram mais tempo pastejando durante o dia. No período de ócio noturno os muares apresentaram menor tempo, em média 3 horas a menos que as demais categorias.

No tempo total de ócio foi observada diferença entre categorias, com diferença em média de 2,66 horas a mais de ócio para os cavalos em relação às éguas e 3,99 horas dos cavalos em relação aos muares.

Não houve diferenças estatísticas para as taxas de bocados entre cavalos e éguas. No entanto, os muares apresentaram as menores taxas de bocados, o que pode explicar o maior tempo de pastejo dessa categoria (14,77 horas) (tabela III).

As éguas somaram maior quantidade de bocados diários totais, enquanto os cavalos e mulas somaram menos bocados totais. No

\section{BIBLIOGRAFIA}

Ralston, S.L. 1984. Controls of feeding in horses. J. Anim. Sci., 59: 1354-1361.

SAEG. 1999. UFV. Sistema de análises estatísticas e genéticas - SAEG. Manual do usuário (versão 8.0). Universidade Federal de Viçosa.Viçosa.. $138 \mathrm{p}$.

Seal, A. and C. Plotka. 1983. Age-specific pregnancy rates in feral horses. J. Wildlife Manage., 47: 422-429.

Silva, F.C. 1999.Manual de análises químicas de período noturno o tempo total de bocados concentrou-se nos muares, mas não diferiu dos eqüinos. Este fato se deve, provavelmente, a maior exigência energética de mantença das fêmeas e colaborou com o maior tempo de pastejo e menor tempo de ócio.

\section{CONCLUSÕES}

Existe um diferencial no comportamento ingestivo sob pastejo entre égua, cavalos e mulas, marcado por diferenças nos tempos de pastejo e ócio, o que pode estar relacionado com a energia de mantença ou produtiva de cada categoria. As éguas e mulas aumentaram o seu tempo de pastejo como forma de atingir suas exigências nutricionais, já que não houve diferença na freqüência de bocados.

solos, plantas e fertilizantes. $1^{\text {a }}$ Ed. CNPS. Rio de Janeiro. p. 370.

Zanine, A.M., E.M. Santos, D.J. Ferreira e P.R. Cecon. 2006a. Habito de pastejo de eqüinos em pastagens tropicais de diferentes estruturas. Arq. Cien. Vet. Zoo. UNIPAR., 13: 83-89.

Zanine, A.M., E.M. Santos, H.N. Parente, D.F. Ferreira e F.Q. Almeida. 2006b. Diferenças entre sexos para as atividades de pastejo em eqüinos no nordeste do Brasil. Arch. Zootec.,55: 1-10.

Archivos de zootecnia vol. 58, núm. 223, p. 462. 